\title{
A network pharmacology approach to investigate the pharmacological effects of Guizhi Fuling Wan on uterine fibroids
}

\author{
LIUTING ZENG* ${ }^{*}$ KAILIN YANG*, HUIPING LIU and GUOMIN ZHANG \\ The Basic Medical Laboratory of Hunan University of Chinese Medicine, Changsha, Hunan 410208, P.R. China
}

Received September 20, 2016; Accepted May 15, 2017

DOI: $10.3892 / \mathrm{etm} .2017 .5170$

\begin{abstract}
To investigate the pharmacological mechanism of Guizhi Fuling Wan (GFW) in the treatment of uterine fibroids, a network pharmacology approach was used. Information on GFW compounds was collected from traditional Chinese medicine (TCM) databases, and input into PharmMapper to identify the compound targets. Genes associated with uterine fibroids genes were then obtained from the GeneCards and Online Mendelian Inheritance in Man databases. The interaction data of the targets and other human proteins was also collected from the STRING and IntAct databases. The target data were input into the Database for Annotation, Visualization and Integrated Discovery for gene ontology (GO) and pathway enrichment analyses. Networks of the above information were
\end{abstract}

Correspondence to: Professor Huiping Liu or Professor Guomin Zhang, The Basic Medical Laboratory of Hunan University of Chinese Medicine, 300 Xueshi Road, Changsha, Hunan 410208, P.R. China

E-mail: 1074983953@qq.com

E-mail: 834095773@qq.com

${ }^{*}$ Contributed equally

Abbreviations: GFW, Guizhi Fuling Wan; GO, gene ontology; TGF- $\beta$, transforming growth factor- $\beta$; Wnt, wingless-type; MAPK, mitogen-activated protein kinase; AKT, protein kinase B; UAE, uterine artery embolization; MRgFUS, magnetic resonance imaging-guided focused ultrasound surgery; NSAIDs, non-steroidal anti-inflammatory drugs; GnRHa, gonadotropin releasing hormone agonists; TCM, traditional Chinese medicine; PPI, protein-protein interaction; IGF, insulin-like growth factor; PCNA, proliferating cell nuclear antigen; EGF, epidermal growth factor; PDGF, platelet-derived growth factor; VEGF, vascular endothelial growth factor; FGF, fibroblast growth factor; RTKs, receptor tyrosine kinase; RA, retinoic acid; SPRM, selective progesterone receptor modulator; PI3K, phosphoinositide 3-kinase; mTOR, mechanistic target of rapamycin; $N F-\kappa B$, nuclear factor- $\kappa \mathrm{B}$; Erk, extracellular signal-regulated kinase; MEK, mitogen-activated protein kinase kinase; ER, estrogen receptor; PR, progesterone receptor; Bcl-2; B-cell lymphoma 2

Key words: Guizhi Fuling Wan, uterine fibroids, mechanism, formula, network pharmacology constructed and analyzed using Cytoscape. The following networks were compiled: A compound-compound target network of GFW; a herb-compound target-uterine fibroids target network of GWF; and a compound target-uterine fibroids target-other human proteins protein-protein interaction network, which were subjected to GO and pathway enrichment analyses. According to this approach, a number of novel signaling pathways and biological processes underlying the effects of GFW on uterine fibroids were identified, including the negative regulation of smooth muscle cell proliferation, apoptosis, and the Ras, wingless-type, epidermal growth factor and insulin-like growth factor-1 signaling pathways. This network pharmacology approach may aid the systematical study of herbal formulae and make TCM drug discovery more predictable.

\section{Introduction}

Uterine fibroids is the most common type of tumor to occur in the female reproductive tract, and develops from the clonal proliferation of single smooth muscle cells of the myometrium, initially caused by cellular genetic changes $(1,2)$. Alterations in complex signaling pathways involving factors such as steroids, growth factors, transforming growth factor $\beta$ (TGF- $\beta$ )/Smad, wingless-type (Wnt)/ $\beta$-catenin, retinoic acid (RA) serve an important role in the development of uterine fibroids $(3,4)$. Furthermore, these signaling factors may regulate multiple pathways through common factors, such as mitogen-activated protein kinase (MAPK) and protein kinase B (also known as Akt) (4). The major risk factors that promote tumor development include genetic, hormonal, immunological and environmental factors (1-4). At present, besides surgical approaches such as hysterectomy, myomectomy, uterine artery embolization (UAE) and magnetic resonance imaging-guided focused ultrasound surgery (MRgFUS) (5), the pharmacological strategies for uterine fibroids focus on relieving symptoms and slowing or arresting tumor development. Three main types of therapeutic are used to reduce symptoms and inhibit the proliferation of fibroids $(6,7)$, namely non-steroidal anti-inflammatory drugs (NSAIDs) (8), gonadotropin releasing hormone agonists (GnRHa) (9) and synthetic steroids with antiprogesterone activity, including mifepristone and asoprisnil (10). As a therapeutic strategy, surgery is associated with operative mortality and morbidity (11), and medicinal therapy is similarly limited because of its side effects. GnRHa 
may relieve bleeding and bulk-related symptoms, but may also cause significant menopausal side effects $(12,13)$. Furthermore, progesterone antagonists and other hormonal therapies that alter estrogen and progesterone production or function may affect fertility (14).

As an important component of complementary and alternative medicine, Chinese herbal formulas, including Guizhi Fuling Wan (GFW), are utilized for the treatment of uterine fibroids (15). A previous bibliometrics study of modern literature that analyzed the names of diseases treated with Guizhi Fuling pills demonstrated that the formula was most frequently used to treat abdominal masses (zheng jia) in traditional Chinese medicine (TCM) and uterine fibroids in western medicine (15).

GFW was first described in Essential Prescriptions from the Golden Cabinet (Jingui Yaolue) (16). The traditional effects of the GFW formula are considered to be invigoration of the blood, prevention of blood stasis and reduction of masses. GFW is composed of Cinnamomi Ramulus (Gui Zhi), Poria Cocos (Schw.) Wolf. (Fuling), Cortex Moutan (Mu Dan Pi), Radix Paeoniae Rubra (Chi Shao) and Persicae Semen (Tao Ren) $(16,17)$. A previous systematic review of 38 randomized controlled trials involving 3,816 participants demonstrated that compared with mifepristone alone, GFW or GFW plus mifepristone reduced the volume of fibroids and improved dysmenorrhea to a greater extent, and were considered to be safer (18). This suggests that GFW may be a potential alternative medicine for the treatment of uterine fibroids; however, its pharmacological mechanism is not well understood.

Chinese formulas are multi-target, multi-component recipes that achieve their specific therapeutic efficacy through active components that regulate molecular networks within the body (19). Therefore, novel methods and tactics are required to systematically investigate and explain the mechanism of Chinese formulas. Network pharmacology, combined with pharmacology and pharmacodynamics, is a novel research field that is involved in the application of omics and systems biology-based technologies (20). As Chinese formulas are considered to have multiple targets, pathways, components and specificities, as necessary factors for the treatment of multiple complex illnesses, network pharmacology methods are suitable for investigating prior knowledge regarding the combination rules of TCM herbal formulae (21). Based on a previous study by Zheng et al (22), the present study selected a network pharmacology approach to uncover the pharmacological mechanism of GFW in the treatment of uterine fibroids.

\section{Materials and methods}

\section{Data preparation}

Composite compounds of the GFWherbs. To collect data on the compounds of GFW, the TCM Database@Taiwan (http://tcm .cmu.edu.tw/zh-tw/), as a comprehensive TCM database previously used to identify TCMs for osteoarthritis (23), and the Traditional Chinese Medicine Systems Pharmacology Database (ibts.hkbu.edu.hk/LSP/tcmsp.php), as a systems pharmacology platform for Chinese herbal medicines (24), were used, along with related literature (25). A total of 565 herbal compounds were identified; 230 in Cinnamomi Ramulus, 55 in Poria Cocos (Schw.) Wolf., 78 in Cortex Moutan, 135 in Radix Paeoniae
Rubra and 67 in Persicae Semen. Combined with related literature (25), 28 active compounds were identified: Cinnamic acid, cinnamic aldehyde, 3-(2-methoxyphenyl)-2-propenal, polyporenic acid $\mathrm{C}$, pachymic acid, dehydrotrametenolic acid, trametenolic acid, gallic acid, oxypaeoniflorin, (+)-catechin, apiopaeonoside, paeonilide, paeoniflorin, suffruticoside B, suffruticoside D, galloylpaeoniflorin, tetragalloylglucopyranose, pentagalloylglucopyranose, benzoic acid, mudanpioside $\mathrm{H}$, hexagalloylglucopyranose, benzoyloxy paeoniflorin, mudanpioside $\mathrm{C}$, benzoylalbiflorin, paeonol, benzoylpaeoniflorin, albiflorin and amygdalin.

Compound target of each GFW herb. All the active compounds were input into SciFinder (http://scifinder.cas.org), a database of chemical and bibliographic information provided by the Chemical Abstracts Service (Columbus, OH, USA), and the molecular structure of each compound was obtained. The structures were drawn in ChemBioDraw 14.0 (PerkinElmer, Inc., Waltham, MA, USA) and saved as 'mol2' file format. These files were imported into PharmMapper (lilab.ecust.edu.cn/pharmmapper), a web server that uses a pharmacophore mapping approach for potential drug target identification (26). Using this web server, the targets of all compounds were identified, excluding that of cinnamic aldehyde as the target data for cinnamic aldehyde was not obtained via the PharmMapper prediction. Due to non-standard naming of the compound targets, the UniProt Knowledgebase (www.uniprot .org/) was used. The protein names were input with the species limited to 'homo sapiens' to obtain official symbols. Following these procedures, the compound targets with official symbols were obtained from the UniProt Knowledgebase.

Uterine fibroids targets. Genes associated with uterine fibroids were identified with two resources; i) GeneCards (www .genecards.org), as a database containing information on genes and their products and biomedical applications, provided by the Weizmann Institute of Science (Rehovot, Israel) and ii) the Online Mendelian Inheritance in Man database (www.omim .org), which catalogues all known diseases with a genetic component and, when possible, links them to relevant genes in the human genome, providing references for further research and tools for genomic analysis of catalogued genes (27). These databases were searched using the keywords 'uterine fibroids', 'uterine fibromas' and 'leiomyoma uterine', which identified a total of 114 genes.

Protein-protein interaction (PPI) data. Data on PPIs was obtained from STRING (http://string-db.org/; version 10), with the species limited to 'homo sapiens' and a confidence score $>0.4$, and InAct (www.ebi.ac.uk/intact/; version 4.2.4). STRING is a database of known and predicted protein-protein interactions (28) and InAct provides an open source database and analytical tool for molecular interaction data (29).

\section{Network construction}

Network construction method. The following networks were constructed: A compound-compound target network of GFW; a herb-compound target-uterine fibroids target network of GFW; and a compound target-uterine fibroids target-other human proteins PPI network. The network analysis software Cytoscape (www.cytoscape.org; version 3.2.1) was used to 


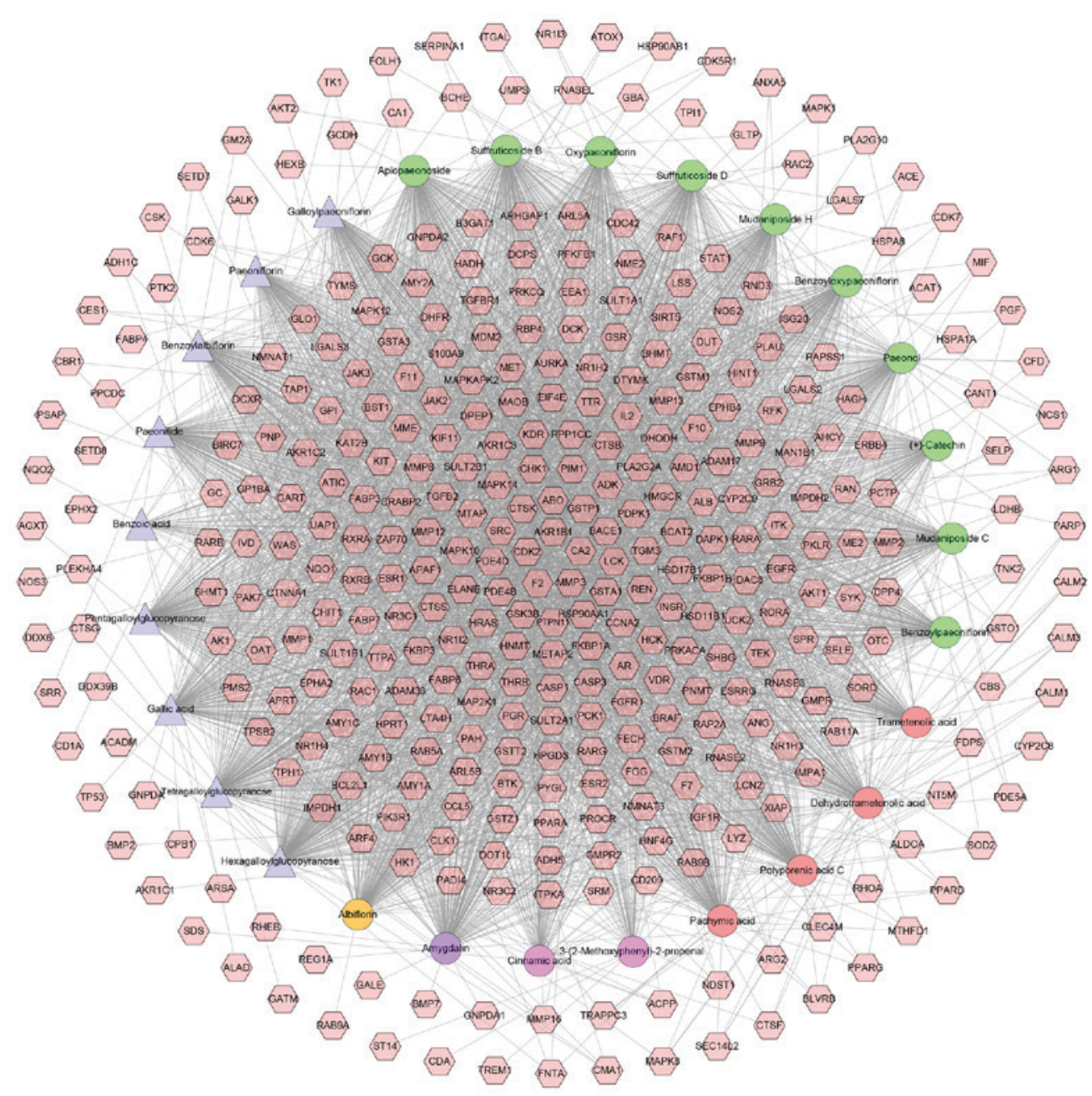

Figure 1. Compound-compound target network of Guizhi Fuling Wan. This network comprised of 362 compound targets and 27 compounds. Pink hexagons represent the compound targets; pink, red, green, orange and purple circles indicate compounds of Cinnamomi Ramulus, Poria Cocos (Schw.) Wolf., Cortex Moutan, Radix Paeoniae Rubra and Persicae Semen, respectively; and blue triangles indicate the common compounds of Cortex Moutan and Radix Paeoniae Rubra.

construct networks. Cytoscape is a software that may be used to visualize biological pathways and intermolecular interaction networks, among others. Furthermore, it provides a basic set of features for data integration, analysis and visualization for complicated network analysis (30).

Network topological feature set definition. The nodes in each network were evaluated based on three indices: Degree, node betweenness and node closeness. Degree indicates the number of edges between a node and other nodes in a network (31). Node betweenness evaluates the participation of a node in the shortest parts of a network and reflects the capability of nodes to manage the rate of information flow in the network (32). Node closeness represents the inverse of the sum of the distance from node i (any given node) to other nodes (33). The importance of a node in a network is indicated by the values of these indices, with higher values indicating greater importance (22).

Enrichment analysis. Gene ontology (GO) and pathway enrichment analyses were also performed on the target data, using the Database for Annotation, Visualization and Integrated Discovery (DAVID; david.ncifcrf.gov/; version 6.8) (34). P-values were derived from the DAVID database and are modified Fisher exact P-values. Smaller P-values indicated greater enrichment (34).

\section{Results}

Compound-compound target network analysis. All active compounds, their targets and the interactions between them (excluding cinnamic aldehyde) are presented in Fig. 1. This network includes 389 nodes (362 compound targets and 27 compounds) and 3,500 edges. Nodes closer to the center exhibit more interactions with compounds than peripheral nodes, which indicates that numerous compound targets may be regulated by multiple compounds rather than a single compound. Coagulation factor II (also known as prothrombin), matrix metalloproteinase 3, carbonic anhydrase 2, aldo-keto reductase family 1 member $\mathrm{B}$ and cyclin dependent kinase 2 (in Fig. 1, F2, MMP3, CA2, AKR1B1 and CDK2, respectively) may be controlled by all of the active compounds.

Herb-compound target-uterine fibroids target network analysis. To understand the relationship between herbs of the GFW formula, compound targets and uterine fibroids targets, a herb-compound target-uterine fibroids target 


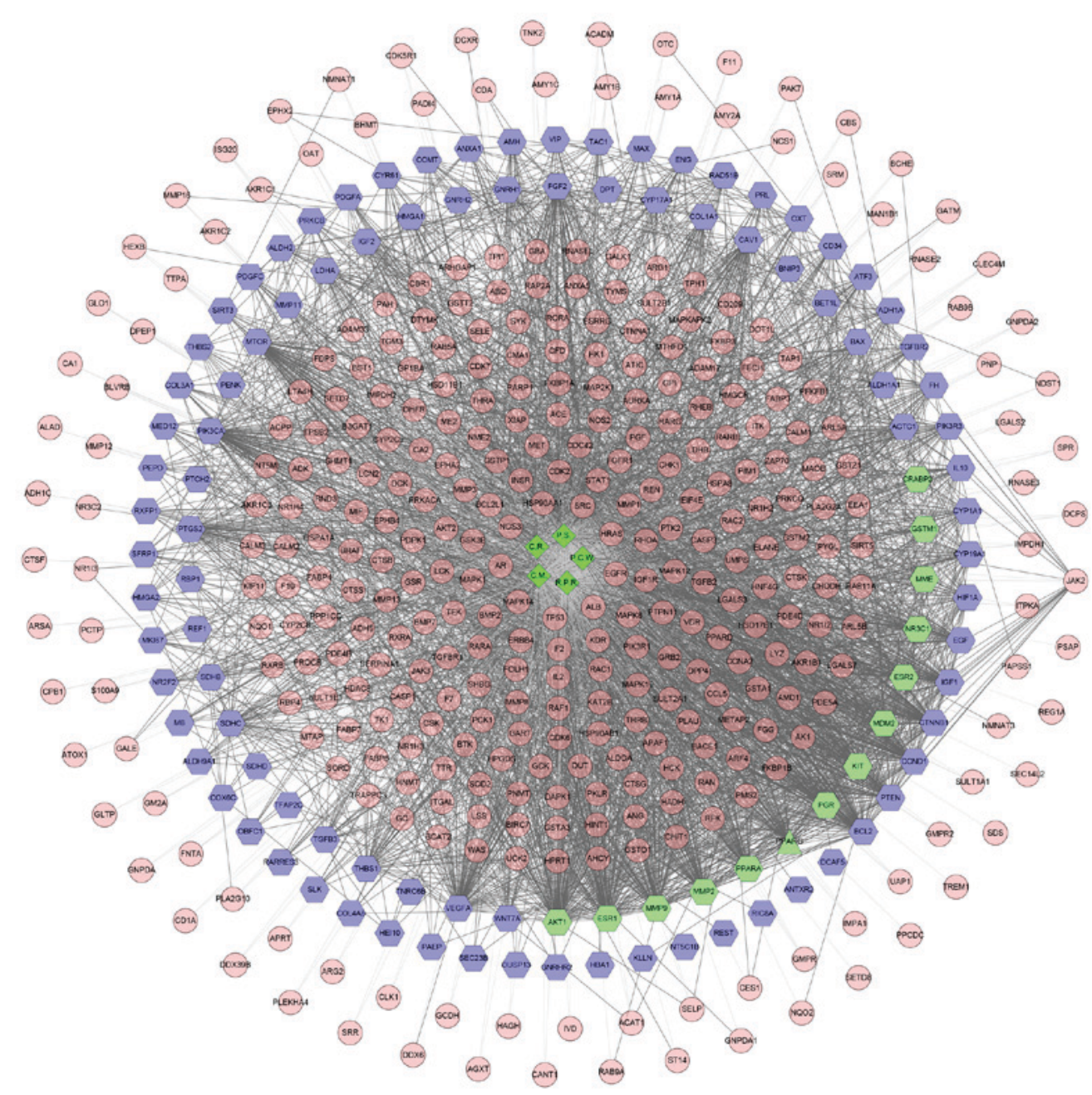

Figure 2. Herb-compound target-uterine fibroids target network of Guizhi Fuling Wan. Green diamonds, pink circles, blue hexagons and green hexagon represent the herbs, compound targets, uterine fibroids targets and compound-uterine fibroids targets, respectively; light lines indicate associations between herbs and other nodes; and dark lines indicate associations between fibroids targets, compound-uterine fibroids targets and compound targets. C.R., Cinnamomi Ramulus; C.M., Cortex Moutan; P.S., Persicae Semen; P.C.W., Poria Cocos (Schw.) Wolf.; R.P.R., Radix Paeoniae Rubra.

network was constructed. It was composed of 459 nodes (5 herbs, 362 compound targets, 78 uterine fibroids targets and 14 compound-uterine fibroids targets) and 3,736 edges (Fig. 2).

According to GO enrichment analysis, these targets were significantly associated with the steroid hormone-mediated signaling pathway (GO ID: 0043401; fold enrichment=16.1; $\mathrm{P}<0.001$ ), response to estrogen (GO ID: 0043627; fold enrichment $=8.4 ; \mathrm{P}<0.001$ ), response to estradiol (GO ID: 0032355; fold enrichment=7.5; $\mathrm{P}<0.001$ ), response to progesterone (GO ID: 0032570; fold enrichment=6.4; $\mathrm{P}<0.001$ ), vascular endothelial growth factor (VEGF) receptor signaling pathway (GO ID: 0048010; fold enrichment=5.3; P<0.001), epidermal growth factor (EGF) receptor signaling pathway (GO ID: 0007173; fold enrichment=4.3; $\mathrm{P}<0.001$ ), fibroblast growth factor (FGF) receptor signaling pathway (GO ID: 0008543; fold enrichment $=4.4 ; \mathrm{P}<0.001)$, insulin-like growth factor (IGF) receptor signaling pathway (GO ID: 0048009; fold enrichment $=10.4 ; \mathrm{P}=0.0058$ ), negative regulation of cell proliferation (GO ID: 0008285; fold enrichment=3.1; $\mathrm{P}<0.001$ ), negative regulation of smooth muscle cell proliferation (GO ID: 0048662; fold enrichment $=8.9$; $\mathrm{P}<0.001$ ), RA receptor signaling pathway (GO ID: 0048384; fold enrichment=15.1;
$\mathrm{P}<0.001)$, response to vitamin A (GO ID: 0033189; fold enrichment=13.5; $\mathrm{P}<0.001$ ), response to RA (GO ID: 0032526; fold enrichment $=6.2 ; \mathrm{P}<0.001)$, TGF- $\beta$ receptor signaling pathway (GO ID: 0007179; fold enrichment=4.1; $\mathrm{P}<0.001$ ), negative regulation of the TGF- $\beta$ receptor signaling pathway (GO ID: 0030512; fold enrichment $=4.4 ; \mathrm{P}<0.001$ ), positive regulation of apoptotic processes (GO ID: 0043065; fold enrichment=2.8; $\mathrm{P}<0.001$ ) and apoptotic processes (GO ID: 0006915; fold enrichment=2.0; $\mathrm{P}<0.001$; Table I and Fig. 3).

Through pathway enrichment, it was observed that compound targets and uterine fibroids targets were primarily related to the phosphoinositide 3-kinase (PI3K)-Akt signaling pathway (fold enrichment $=3.0 ; \mathrm{P}<0.001$ ), Ras signaling pathway (fold enrichment=3.6; $\mathrm{P}<0.001$ ), MAPK signaling pathway (fold enrichment=2.3; $\mathrm{P}<0.001$ ), estrogen signaling pathway (fold enrichment=4.7; $\mathrm{P}<0.001$ ), VEGF signaling pathway (fold enrichment=6.7; $\mathrm{P}<0.001)$, mechanistic target of rapamycin (mTOR) signaling pathway (fold enrichment=5.1; $\mathrm{P}<0.001$ ), Wnt signaling pathway (fold enrichment=1.9; $\mathrm{P}=0.032$ ), apoptosis (fold enrichment=3.6; $\mathrm{P}<0.001$ ), EGF signaling pathway (fold enrichment=3.8; $\mathrm{P}<0.001$ ), IGF-1 signaling pathway (fold enrichment $=4.5 ; \mathrm{P}<0.001)$, role of ErbB2 receptor tyrosine 


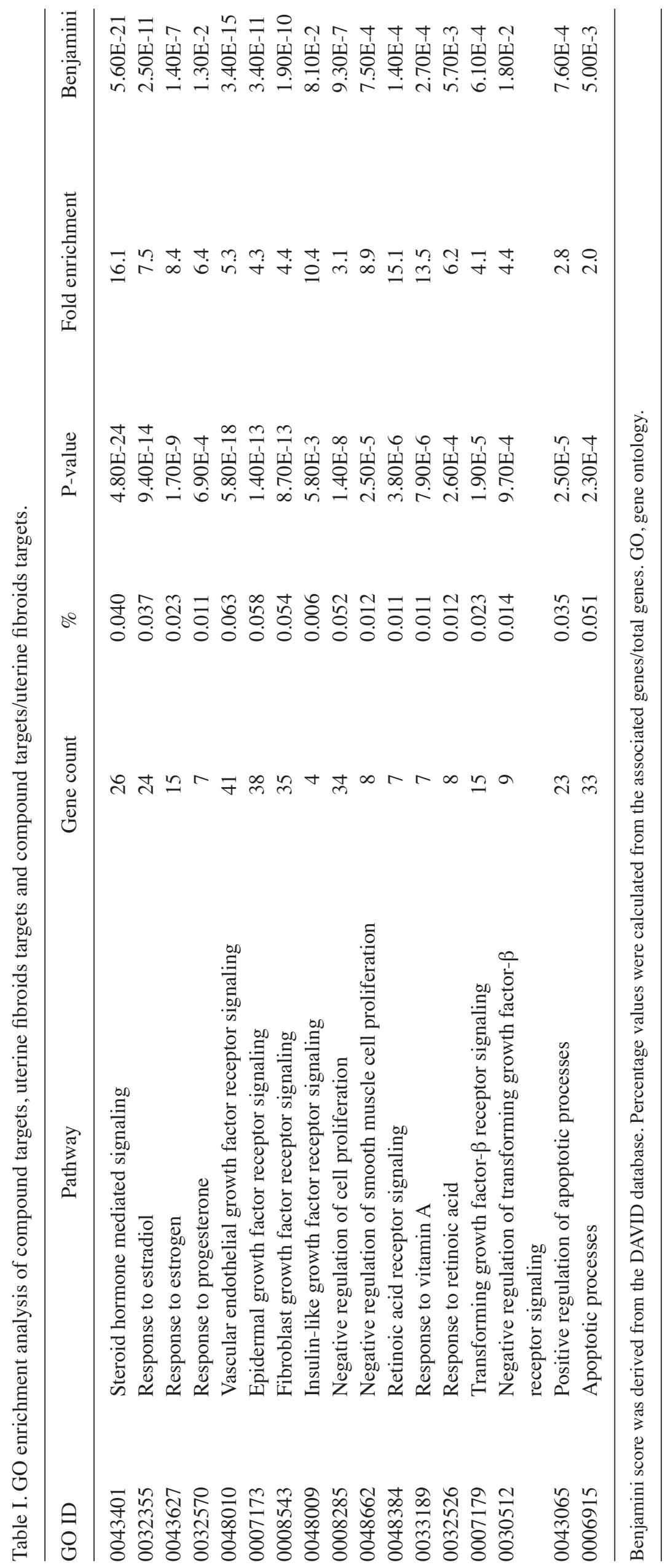




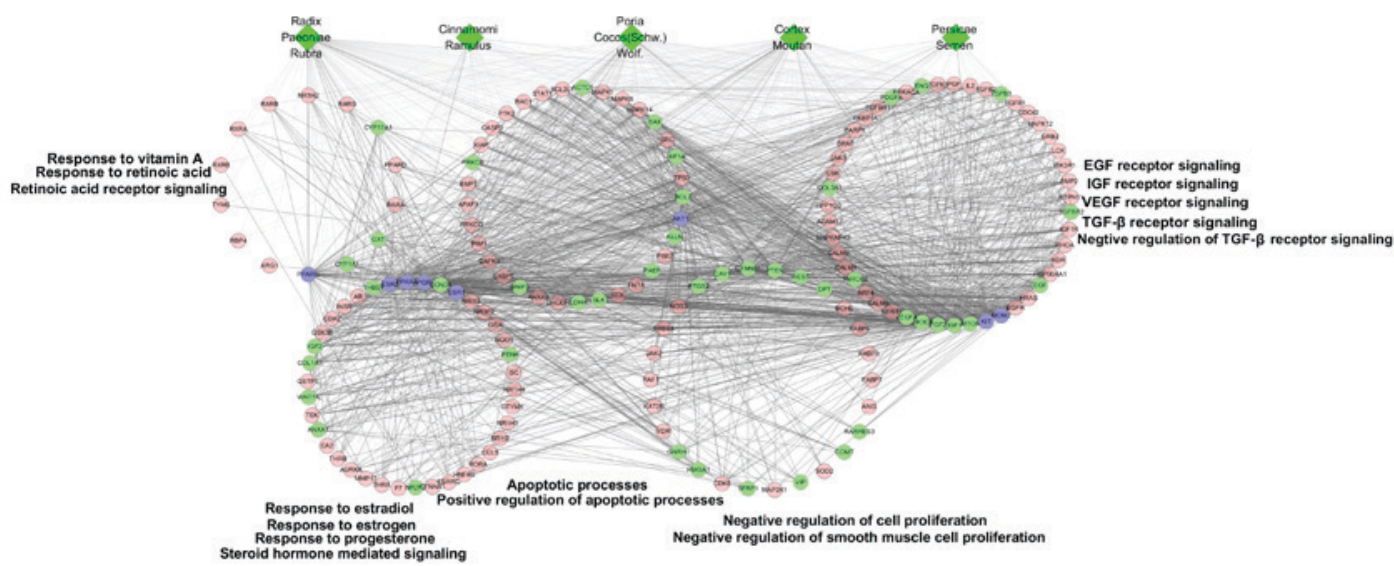

Figure 3. GO enrichment analysis of compound targets, uterine fibroids targets and compound target/uterine fibroids targets. According to the associated biological processes, compound targets of Guizhi Fuling Wan and uterine fibroids targets were related to various molecular mechanisms of uterine fibroids. Green diamonds, pink circles, green circles and blue circles represent the herbs, compound targets, uterine fibroids targets and compound-uterine fibroids targets, respectively; light lines indicate associations between herbs and other nodes; and dark lines indicate associations between compound-uterine fibroids targets and compound targets. EGF, epidermal growth factor; FGF, fibroblast growth factor; IGF, insulin-like growth factor; VEGF, vascular endothelial growth factor; TGF- $\beta$, transforming growth factor $\beta$.

kinase 2 in signal transduction and oncology (fold enrichment=4.1; $\mathrm{P}<0.001)$, platelet-derived growth factor $(\mathrm{PDGF})$ signaling pathway (fold enrichment $=3.3 ; \mathrm{P}=0.0016$ ), TGF- $\beta$ signaling pathway (fold enrichment $=2.2 ; \mathrm{P}=0.033$ ), nuclear factor- $\mathrm{\kappa B}(\mathrm{NF}-\kappa \mathrm{B})$ signaling pathway (fold enrichment=2.1; $\mathrm{P}=0.043$ ), extracellular signal-regulated kinase (Erk)1/Erk2 MAPK signaling pathway (fold enrichment $=2.5 ; \mathrm{P}=0.033$; Table II and Fig. 4)

Compound target-uterine fibroids target-other human proteins PPI network analysis. This network contained 2,112 nodes and 67,861 edges (Fig. 5). In this network, nodes with indices higher than the average values (gegree $\geq 0.0006257$, node betweenness $\geq 0.4363$, closeness $\geq 64.26$ ) were regarded as main nodes. A total of 337 main nodes were selected for GO and pathway enrichment analyses.

Based on GO enrichment analysis, a direct interaction network between the main nodes was established. As depicted in Fig. 6, the main nodes were divided into four functional modules. Module 1 is associated with cell proliferation including negative regulation of cell proliferation (GO ID: 0008285; fold enrichment $=4.6 ; \mathrm{P}<0.001$ ) and negative regulation of smooth muscle cell proliferation (GO ID: 0048662; fold enrichment $=8.9 ; \mathrm{P}<0.001$ ). Module 2 is associated with the response of cells to steroid hormones including steroid hormone-mediated signaling pathway (GO ID: 0043401; fold enrichment=10.0; $\mathrm{P}<0.001$ ), response to estrogen (GO ID: 0043627; fold enrichment=9.8; $\mathrm{P}<0.001$ ) and response to estradiol (GO ID: 0032355; fold enrichment=9.2; $\mathrm{P}<0.001$ ). Module 3 is associated with apoptosis including positive regulation of apoptotic processes (GO ID: 0043065; fold enrichment=5.6; $\mathrm{P}<0.001)$ and the apoptotic signaling pathway (GO ID: 0097190; fold enrichment=4.1; $\mathrm{P}<0.001$ ). Module 4 is associated with the response of cells to growth factors including VEGF receptor signaling pathway (GO ID: 0048010; fold enrichment=9.3; $\mathrm{P}<0.001)$, EGF receptor signaling pathway (GO ID: 0007173; fold enrichment=9.7; P $<0.001$ ), FGF receptor signaling pathway (GO ID: 0008543; fold enrichment=10.1;
$\mathrm{P}<0.001$ ), IGF receptor signaling pathway (GO ID: 0048009; fold enrichment $=14.0 ; P=0.0026)$, TGF- $\beta$ receptor signaling pathway (GO ID: 0007179; fold enrichment=10.9; $\mathrm{P}<0.001$ ), negative regulation of the TGF- $\beta$ receptor signaling pathway (GO ID: 0030512; fold enrichment=7.2; $\mathrm{P}<0.001$ ). These data are presented in Table III.

Pathway enrichment analysis of the major nodes indicated that the nodes were primarily related to the PI3K-Akt signaling pathway (fold enrichment $=4.6 ; \mathrm{P}<0.001$ ), Ras signaling pathway (fold enrichment $=5.1 ; \mathrm{P}<0.001$ ), MAPK signaling pathway (fold enrichment $=3.8 ; \mathrm{P}<0.001$ ), estrogen signaling pathway (fold enrichment $=8.5 ; \mathrm{P}<0.001$ ), ErbB signaling pathway (fold enrichment $=9.0 ; \mathrm{P}<0.001$ ), VEGF signaling pathway (fold enrichment $=10.7 ; \mathrm{P}<0.001$ ), mTOR signaling pathway (fold enrichment $=2.8 ; \mathrm{P}=0.0056$ ), Wnt signaling pathway (fold enrichment $=3.6 ; \mathrm{P}<0.001$ ), apoptosis (fold enrichment $=4.9 ; \mathrm{P}<0.001$ ), EGF signaling pathway (fold enrichment=5.4; $\mathrm{P}<0.001$ ), IGF-1 signaling pathway (fold enrichment $=5.9 ; \mathrm{P}<0.001$ ), TGF- $\beta$ signaling pathway (fold enrichment=3.9; $\mathrm{P}<0.001$ ) and NF- $\mathrm{KB}$ signaling pathway (fold enrichment=4.0; $\mathrm{P}<0.001$; Table IV and Fig. 7).

\section{Discussion}

At present there is a lack of effective treatment for uterine fibroids. The therapeutic strategies used in western medicine include surgical treatment and pharmacological strategies, though both achieve unsatisfactory outcomes (12-14). TCM recipes exert therapeutic effects on a number of incurable diseases, including uterine fibroids (15). Due to the multi-component and multi-target features of TCM, the research approach for TCM should be different to that of western medicine. However, many studies still apply the conventional research approach of 'one drug, one target, one illness', which does not account for the multi-target and multi-component characteristics of TCM recipes (19-22).

Due to the development of bioinformatics, the network approach has become a novel means of efficiently and 
Table II. Pathway enrichment analysis of compound targets, uterine fibroids targets and compound targets/uterine fibroids targets.

\begin{tabular}{|c|c|c|c|c|c|}
\hline Pathway & Gene count & $\%$ & P-value & Fold enrichment & Benjamini \\
\hline Phosphoinositide 3-kinase/ Akt signaling & 56 & 0.086 & $9.10 \mathrm{E}-14$ & 3.0 & $2.70 \mathrm{E}-12$ \\
\hline Ras signaling & 44 & 0.068 & $1.20 \mathrm{E}-13$ & 3.6 & $3.30 \mathrm{E}-12$ \\
\hline MAPK signaling & 32 & 0.049 & $1.30 \mathrm{E}-5$ & 2.3 & $6.80 \mathrm{E}-5$ \\
\hline Estrogen signaling & 25 & 0.038 & $2.30 \mathrm{E}-10$ & 4.7 & $2.80 \mathrm{E}-9$ \\
\hline Vascular endothelial growth factor signaling & 22 & 0.034 & $2.10 \mathrm{E}-12$ & 6.7 & $4.60 \mathrm{E}-11$ \\
\hline Mechanistic target of rapamycin signaling & 16 & 0.025 & $2.40 \mathrm{E}-7$ & 5.1 & $1.60 \mathrm{E}-6$ \\
\hline Wingless-type signaling & 14 & 0.022 & $3.20 \mathrm{E}-2$ & 1.9 & $7.10 \mathrm{E}-2$ \\
\hline Apoptosis & 12 & 0.018 & $3.90 \mathrm{E}-4$ & 3.6 & $1.50 \mathrm{E}-3$ \\
\hline Epidermal growth factor signaling & 11 & 0.017 & $2.40 \mathrm{E}-4$ & 3.8 & $4.50 \mathrm{E}-3$ \\
\hline Insulin-like growth factor-1 signaling & 10 & 0.015 & $1.30 \mathrm{E}-4$ & 4.5 & $3.20 \mathrm{E}-3$ \\
\hline $\begin{array}{l}\text { Role of ErbB } 2 \text { receptor tyrosine kinase } 2 \text { in } \\
\text { signal transduction and oncology }\end{array}$ & 10 & 0.015 & $3.10 \mathrm{E}-4$ & 4.1 & $5.30 \mathrm{E}-3$ \\
\hline Platelet-derived growth factor signaling & 10 & 0.015 & $1.60 \mathrm{E}-3$ & 3.3 & $1.70 \mathrm{E}-2$ \\
\hline Transforming growth factor- $\beta$ signaling & 10 & 0.015 & $3.30 \mathrm{E}-2$ & 2.2 & $7.20 \mathrm{E}-2$ \\
\hline Nuclear factor- $\kappa \mathrm{B}$ signaling & 10 & 0.015 & 4.30E-2 & 2.1 & $9.00 \mathrm{E}-2$ \\
\hline $\begin{array}{l}\text { Extracellular signal-regulated kinase } \\
\text { 1/2-MAPK signaling }\end{array}$ & 8 & 0.012 & $3.30 \mathrm{E}-2$ & 2.5 & $1.50 \mathrm{E}-1$ \\
\hline
\end{tabular}

Benjamini score was derived from the DAVID database. Percentage values were calculated from the associated genes/total genes.

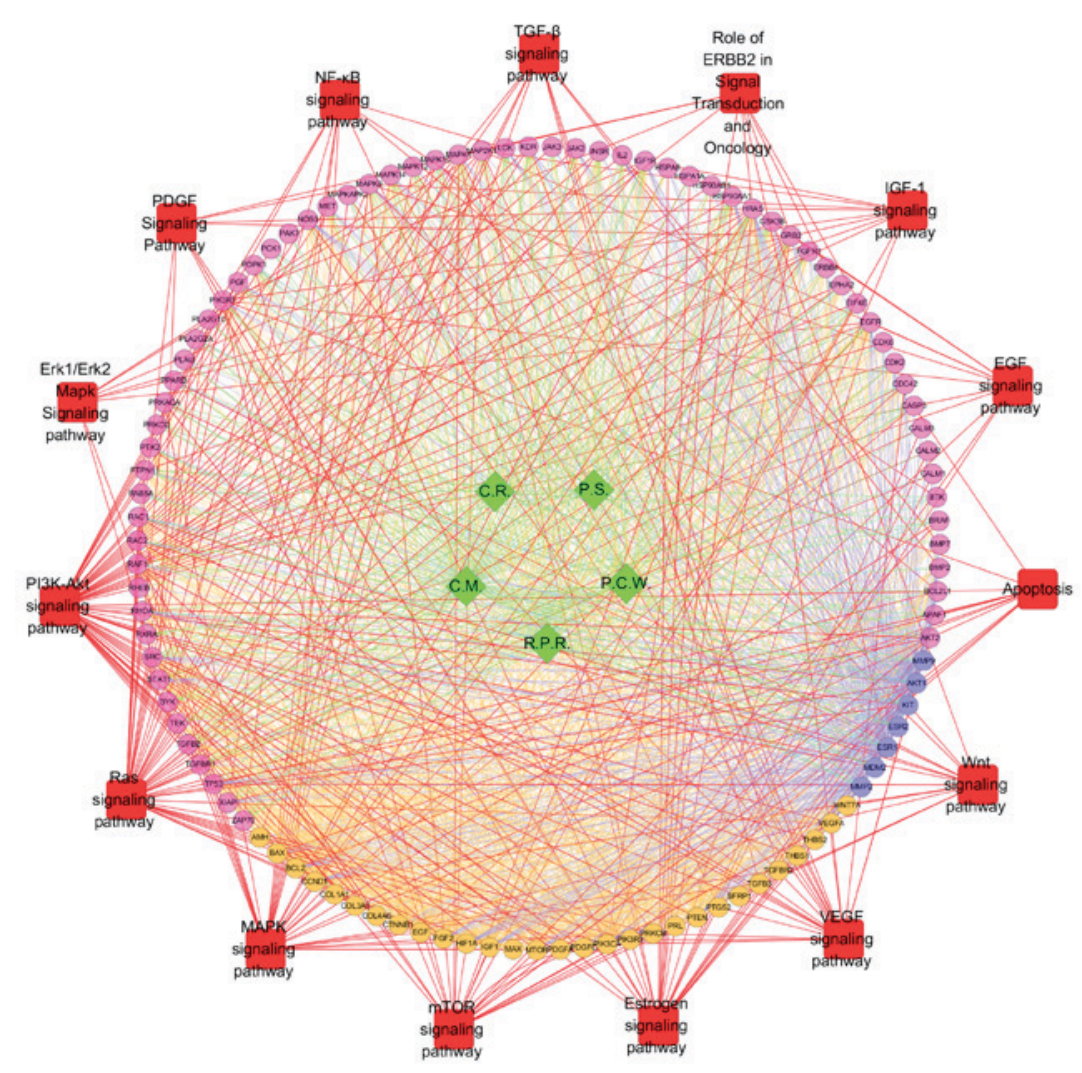

Figure 4. Pathway enrichment analysis of compound targets, uterine fibroids targets and compound targets/uterine fibroids targets. According to pathway enrichment analysis, compound targets of GFW and uterine fibroids targets were related to various pathways. Green diamonds and pink, orange and blue circles represent the herbs, compound targets, uterine fibroids targets and compound-uterine fibroids targets, respectively; Red squares indicate the pathway; red lines indicate the associations between pathways and targets; green lines indicate the associations between herbs and targets; orange lines indicate the associations between uterine fibroids targets and other nodes; and blue lines indicate the associations between compound-uterine fibroids targets and other nodes. PI3K, phosphoinositide 3-kinase; Akt, protein kinase B; Erk, extracellular signal-regulated kinase; NF- $\mathrm{BB}$, nuclear factor-kB; TGF- $\beta$, transforming growth factor- $\beta$; IGF, insulin-like growth factor; EGF, epidermal growth factor; Wnt, wingless-type; VEGF, vascular endothelial growth factor; mTOR, mechanistic target of rapamycin; MAPK, mitogen-activated protein kinase; PDGF, platelet-derived growth factor; C.R., Cinnamomi Ramulus; C.M., Cortex Moutan; P.S., Persicae Semen; P.C.W., Poria Cocos(Schw.) Wolf.; R.P.R., Radix Paeoniae Rubra. 


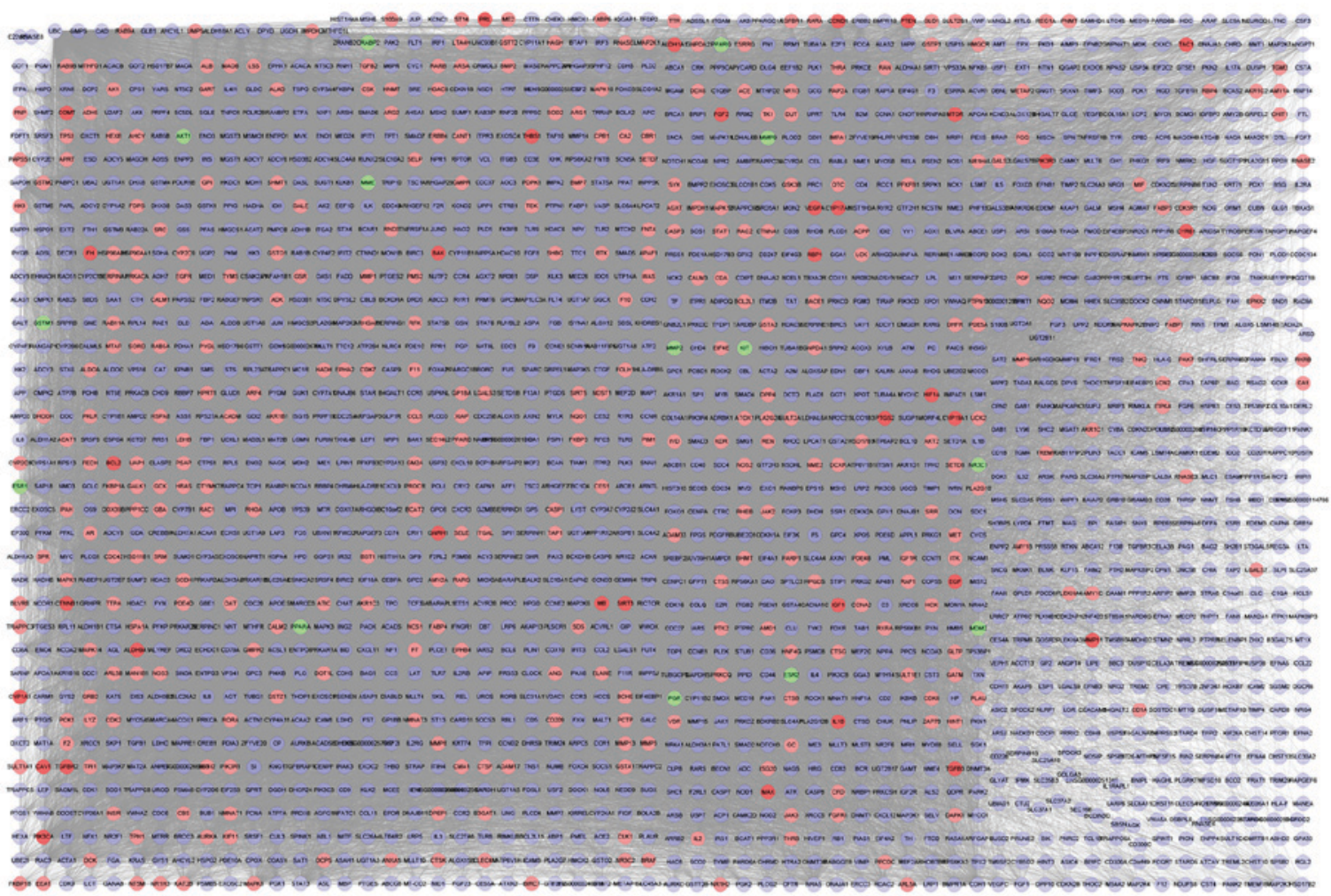

Figure 5. Compound target-uterine fibroids target-other human proteins protein-protein interaction network. Blue, pink, green and red circles indicate the other human proteins, compound targets, compound-uterine fibroids targets and uterine fibroids targets, respectively. The lines represent the nodes associated through protein-protein interactions.

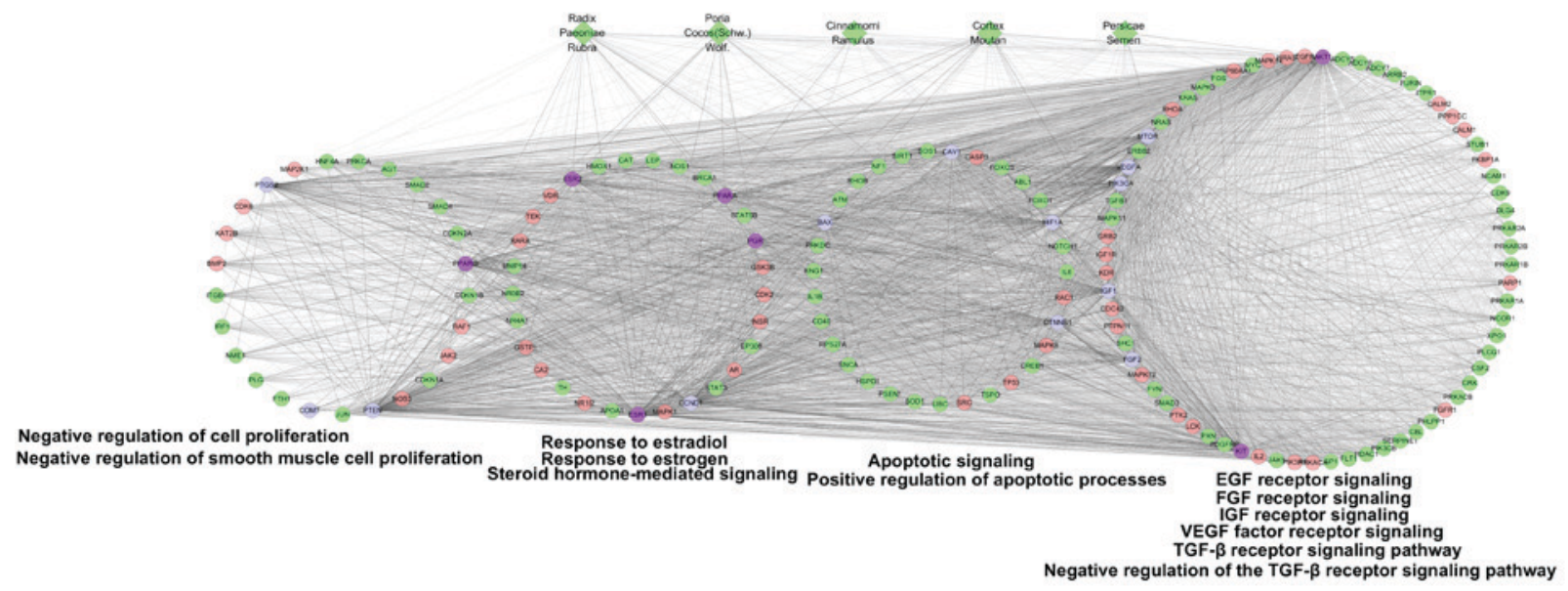

Figure 6. GO enrichment analysis of compound targets, uterine fibroids targets, compound targets/uterine fibroids targets and other human proteins. According to the associated biological processes, the nodes were categorized into four modules. Green diamonds and pink, green, blue and purple circles indicate the herbs, compound targets, other human proteins, uterine fibroids targets and compound-uterine fibroids targets, respectively; light lines represent associations between herbs and other nodes; and dark lines represent associations between compound targets, other human proteins, uterine fibroids targets and compound-uterine fibroids targets. EGF, epidermal growth factor; FGF, fibroblast growth factor; IGF, insulin-like growth factor; VEGF, vascular endothelial growth factor.

systemically identifying the potential molecular mechanisms of TCM recipes. In the present study, a number of network-based computational methods and algorithm-based approaches were used to predict targets and construct networks, in order to assess the molecular interactions associated with GFW when used as a uterine fibroids therapy.

Other studies have demonstrated that there are numerous pathways associated with the development of uterine fibroids (35-42). In particular, steroid signaling (estrogen and progesterone) has been implicated as a key factor in the progression of uterine fibroids (35-38). Alterations in other signaling pathways involving growth factors and their cognate receptors also promote the growth and development of uterine fibroids (39-42).

Regarding the steroid pathway, aberrant and rapid MAPK signaling responses to estradiol may effect on leiomyoma 


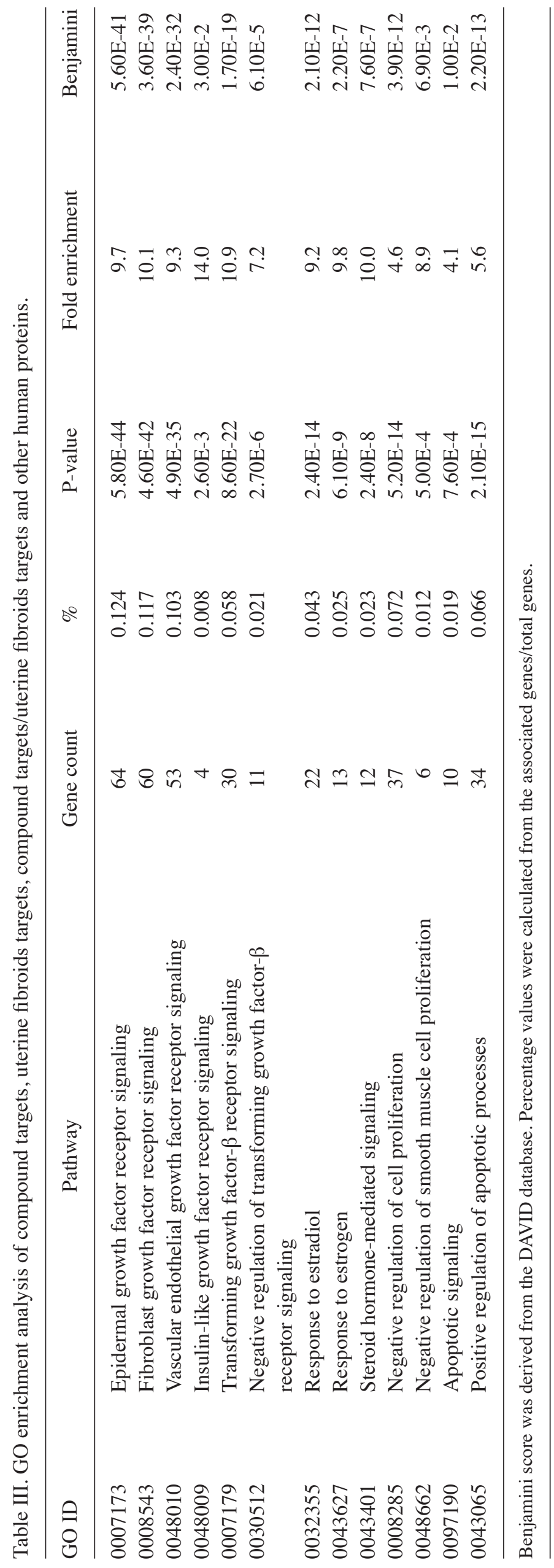


Table IV. Pathway enrichment analysis of compound targets, uterine fibroids targets, compound targets/uterine fibroids targets and other human proteins.

\begin{tabular}{lccccc}
\hline Pathway & Gene count & $\%$ & P-value & Fold enrichment & Benjamini \\
\hline Phosphoinositide 3-kinase/Akt signaling & 73 & 0.142 & $1.30 \mathrm{E}-29$ & 4.6 & $3.80 \mathrm{E}-28$ \\
Ras signaling & 53 & 0.103 & $2.20 \mathrm{E}-23$ & 5.1 & $3.30 \mathrm{E}-22$ \\
Mitogen-activated protein kinase signaling & 45 & 0.087 & $7.20 \mathrm{E}-15$ & 3.8 & $4.40 \mathrm{E}-14$ \\
Estrogen signaling & 39 & 0.076 & $4.60 \mathrm{E}-26$ & 8.5 & $9.90 \mathrm{E}-25$ \\
ErbB signaling & 36 & 0.070 & $6.90 \mathrm{E}-25$ & 9.0 & $1.40 \mathrm{E}-23$ \\
Vascular endothelial growth factor signaling & 30 & 0.058 & $2.60 \mathrm{E}-23$ & 10.7 & $3.70 \mathrm{E}-22$ \\
Wingless-type signaling & 23 & 0.045 & $2.30 \mathrm{E}-7$ & 3.6 & $7.20 \mathrm{E}-7$ \\
Epidermal growth factor signaling & 20 & 0.039 & $1.70 \mathrm{E}-11$ & 5.4 & $8.20 \mathrm{E}-10$ \\
Insulin-like growth factor-1 signaling & 17 & 0.033 & $1.10 \mathrm{E}-10$ & 5.9 & $3.90 \mathrm{E}-9$ \\
Nuclear factor- $\kappa$ B signaling & 16 & 0.031 & $8.10 \mathrm{E}-6$ & 4.0 & $2.20 \mathrm{E}-5$ \\
Transforming growth factor- $\beta$ s signaling & 15 & 0.029 & $2.10 \mathrm{E}-5$ & 3.9 & $5.40 \mathrm{E}-5$ \\
Apoptosis & 14 & 0.027 & $3.50 \mathrm{E}-6$ & 4.9 & $9.70 \mathrm{E}-6$ \\
Mechanistic target of rapamycin signaling & 10 & 0.037 & $5.60 \mathrm{E}-3$ & 2.8 & $2.30 \mathrm{E}-2$
\end{tabular}

Benjamini score was derived from the DAVID database. Percentage values were calculated from the associated genes/total genes.

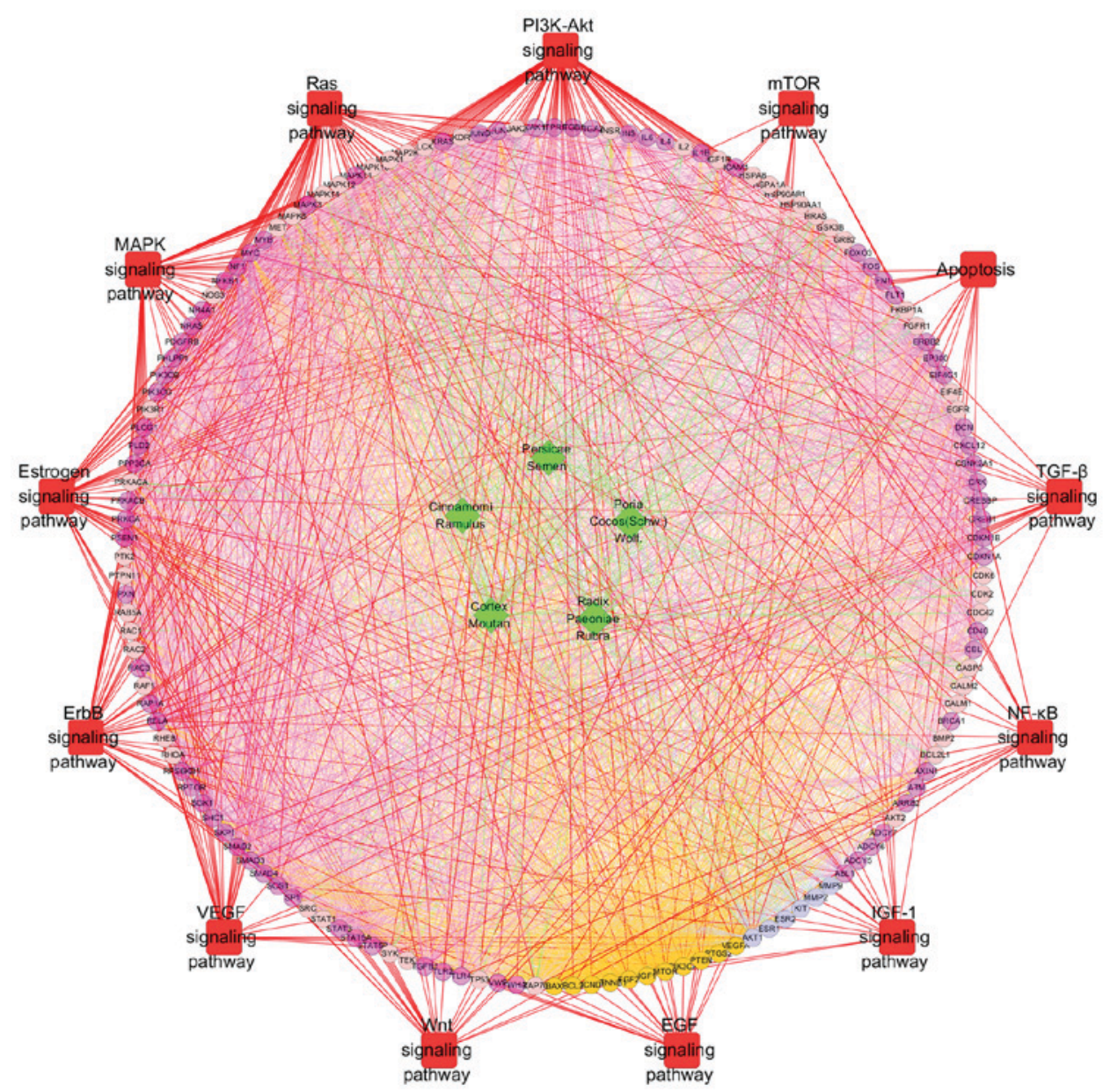

Figure 7. Pathway enrichment analysis of compound targets, uterine fibroids targets, compound targets/uterine fibroids targets and other human proteins. Pathway enrichment indicated that the major nodes were primarily linked to the indicated pathways. Green diamonds and light pink, dark pink, orange and blue circles indicate the herbs, compound targets, other human proteins, uterine fibroids targets and compound-uterine fibroids targets, respectively; red squares indicate the pathways; red lines indicate the associations between pathways and targets; green lines indicate the associations between herbs and targets; orange lines indicate the associations between uterine fibroids targets and other nodes; and blue lines indicate the associations between compound-uterine fibroids targets and other nodes. PI3K, phosphoinositide 3-kinase; Akt, protein kinase B; mTOR, mechanistic target of rapamycin; TGF- $\beta$, transforming

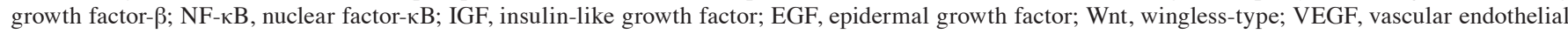
growth factor; MAPK, mitogen-activated protein kinase. 
proliferation (43). It has been observed that compared with the surrounding myometrium, the mRNA transcription of estrogen receptor (ER) $\alpha$ and ER $\beta$ is elevated in leiomyoma tissue (44-45). Maekawa et al (46) demonstrated that epigenetic regulation of ER $\alpha$ through DNA methylation may serve a role in leiomyoma. In addition, it has been reported that progresterone as well as estrogen may serve a significant role in leiomyoma development (38). Compared with estrogen-mediated myometrium proliferation during the menstrual cycle, secretion of progesterone promotes mitotic activity in uterine leiomyomas $(35,38)$. Furthermore, leiomyoma xenograft animal models have indicated the necessity of progesterone for the growth of uterine leiomyoma (47). Progesterone-bound progesterone receptor (PR) can not only accelerate the transcription of specificity protein-1 (SP-1) (35), as a transcription factor itself, but may also activate signaling pathways. For instance, ligand-bound PRs may activate protein kinases involved in growth factor signaling, such as MAPK and MEK (48).

The role of progesterone in the development of uterine fibroids is complex. Estradiol may induce an upregulation in PRs in leiomyoma cells (47), and interactions between progesterone and growth factor signaling may also promote the development of leiomyoma. For instance, progesterone may downregulate the expression of IGF-1 in human leiomyoma cells (49), upregulate the expression of proliferating cell nuclear antigen (PCNA) and EGF, as established regulators of leiomyoma cellular proliferation $(50,51)$, and activate the Akt pathway to mediate leiomyoma proliferation (4). These findings suggest that progesterone signaling is involved in complex signaling networks associated with leiomyoma.

Regarding growth factors, previous studies suggest that alterations in certain growth factors and their cognate receptors or signaling pathways serve a significant role in the growth and development of uterine fibroids (39-42). These factors include IGF-1 $(52,53)$, PDGF (42), VEGF (54), EGF (55), and FGF (56). Activation of receptor tyrosine kinases (RTKs) is a critical biological process; growth factor binding to RTKs leads receptor dimerization and autophosphorylation, thereby activating the downstream pathways Grb2/Sos/Ras/Raf/MEK/Erk and PI3K/PIP3/Akt to regulate proliferation, differentiation, survival and metabolism $(57,58)$. Previous results have indicated that IGF-1 signaling is regulated by estrogen, and that $17 \beta$ estradiol treatment leads to increases in IGF-1 mRNA and Myb, a transcription factor that promotes the expression of cell cycle progression genes in leiomyoma cells (59). Furthermore, estradiol has been demonstrated to promote the upregulation of growth factors and RTKs in uterine leiomyomas, indicating that growth factors and RTKs represent intermediate effectors of sex steroids in leiomyomas (60). It has also been demonstrated that under the influence of estrogen, the Ras/Raf/MEK/ERK signaling pathway $(43,59)$ and PI3K/Akt/mTOR signaling pathway $(57,61,62)$, activated by RTK-ligand complexes, exert significant effects on the pathological growth and development of fibroids. Expression of the Smad signaling pathway mediated by ligands including TGF- $\beta$, activin, mystatin, BMP and others belonging to the TGF- $\beta$ superfamily is also associated with leiomyoma, and is now becoming a potential therapeutic target (63). Furthermore, compared with normal smooth muscle cells, IGF-2 mRNA is upregulated in uterine leiomyoma samples, and levels of IGF-1 are associated with Akt activation (53). In uterine fibroids, both EGF and PDGF have been found to stimulate protein synthesis in leiomyoma and myometrial cells (64). Notably, downstream signaling induced by EGF stimulation is altered in leiomyoma cells when compared with myometrial cells (65).

VEGF was an essential factor for the growth of leiomyoma xenografts in vivo (66-68). Furthermore, its cognate receptors VEGFR-1 and VEGFR-2, and VEGF-A, were significantly overexpressed in leiomyoma when compared with adjacent myometrium (66-68). A recent study on Wnt signaling in the growth and development of uterine fibroids demonstrated that the Wnt/ $\beta$-catenin signaling pathway mediated a novel interaction between leiomyoma stem cells (representing $1 \%$ of tumor cells; also known as a leiomyoma side-population), and mature leiomyoma cells, which promoted tumor growth (69). Furthermore, the paracrine effects of estrogen and progesterone may stimulate leiomyoma cells to proliferate through Wnt/ $\beta$-catenin signaling (69). As an additional factor, RA is an active metabolite of vitamin A (retinol) and primarily promotes cellular growth and development (70). Previous results suggest that receptors of RA signaling (RA and retinoid $\mathrm{X}$ receptors) are expressed in leiomyoma cells (70).

The characteristics of fibroids are principally due to the clonal proliferation of single smooth muscle cells in the myometrium and alterations in complex signal pathways $(3,4)$. The associated signaling pathways are mediated by multiple factors, including steroids, growth factors, TGF- $\beta / \mathrm{Smad}$, Wnt/ $\beta$-catenin and RA $(3,4)$. These signaling molecules in leiomyoma cells serve a common role of mediating secretion from peripheral stromal cells to regulate leiomyoma growth $(3,4)$. The regulation of estrogen and progesterone signaling may be an important method for treating uterine fibroids. For instance, continuous administration of gonadotropin-releasing GnRHa induced menopausal status and lowered estrogen level, which was associated with tumor shrinkage (71). However, due to the side effects of long-term GnRHa use, including loss of bone mineral density (71), it may only be used for a relatively short period. Progesterone antagonist and selective progesterone receptor modulator (SPRM) may inhibit proliferation and induce apoptosis in leiomyoma cells $(72,73)$. Furthermore, SPRM was able to reduce the expression of IGF-1 (43), VEGF (74), EGF and TGF- $\beta$ (75), which inhibits estrogen and progesterone signaling, and the Ras/Raf/MEK/Erk and PI3K/Akt/mTOR signaling pathways (75). Asoprisnil, a SPRM, decreased the expression of certain growth factors and growth factors receptors in leioyoma, including EGFR, IGF-1R $\alpha$ and TGFRII (75). However, its side effects included endometrial hyperplasia and breast pain and discomfort (76).

The TGF- $\beta /$ Smad and RA signaling pathways also represent potential targets for therapeutic development. Previous data indicate that GnRHa may decrease the expression of TGF- $\beta$ receptors, Smad4 and phosphorylated Smad3 (63), and all-trans RA may inhibit the proliferation of leiomyoma cells (77). At present, the major therapeutic agents for uterine leiomyomas are steroids, SPRMs and selective estrogen receptor modulators. However, long-term usage might cause reproductive system side effects (12-14). The present 
experimental data demonstrated that uterine fibroids may also be alleviated by GFW through its downregulatory effects on estrogen, progesterone and their cognate receptors and production of TGF- $\beta /$ Smad.

In uterine fibroids, the upregulation of five key factors, namely steroids, growth factors, TGF- $\beta / \mathrm{Smad}$, Wnt/-catenin and RA, is closely related with tumor growth and development (4). Leiomyoma and peripheral stromal cells cooperate to promote leiomyoma proliferation and increase the synthesis of peripheral matrix proteins (proteoglycans and fibronectins) by paracrine signaling, which forms a complex network involving alterations in cell shape and cytoskeleton $(78,79)$. Thus, regulation of paracrine signaling molecules, as a therapeutic strategy for uterine fibroids, may inhibit the synthesis of matrix proteins and proteoglycans, inhibit the proliferation of leiomyoma cells and promote leiomyoma cell apoptosis (4). Proliferation-related signaling pathways mediated by estrogen and progesterone serve complex and important roles in the pathology of uterine fibroids (39). Thus, use of estrogen and progesterone antagonists, including $\mathrm{GnRHa}$ and synthetic steroids, with progesterone antagonists such as mifepristone and asoprisnil, may effectively inhibit the development of leiomyoma, and warrants further study. Future research should also focus on the potential regulatory effects of GFW on estrogen and progesterone receptors.

Cell apoptosis, particularly of leiomyoma, peripheral stromal and fibroids vascular endothelial cells and leiomyoma stem cells, has been closely associated with fibroids development (4). Leiomyoma stem cells serve roles in the organizational structure and generation of leiomyoma cells, and peripheral matrix synthesis, which contributes to the development of fibroids (4). Thus, inducing the apoptosis of various types of leiomyoma cells is a terminal method for treating uterine fibroids. Previous studies have demonstrated that total paeony glucosides, including paeoniflorin, oxypaeoniflorin, benzoyloxypaeoniflorin, benzoylalbiflorin and albiflorin, may induce tumor cell apoptosis by increasing intracellular $\mathrm{Ca}^{+}$concentration, inhibiting the mRNA transcription of B-cell lymphoma 2 (Bcl-2), Bcl-extra large and upregulating Bcl-2-associated X protein expression $(79,80)$. Furthermore, human leiomyoma cell proliferation may be inhibited by paeonol, pachymic acid, albiflorin and paeoniflorin $(80,81)$. It has also been reported that GFW may promote tumor cell apoptosis and inhibit human leiomyoma cell proliferation $(81,82)$. Therefore, GFW may prevent the growth of uterine fibroids by promoting tumor cell apoptosis.

The uterine fibroids are characterized by excessive deposition of extracellular matrix and proliferation of fibroids, which is mediated by a variety of signaling pathways (4). For instance, receptor-bound growth factors, estradiol and progesterone can activate Ras/Raf/MEK/Erk, and thus inhibition of Ras/Raf/MEK/Erk may be an effective therapeutic strategy, indicating the importance of double- and multi-target treatments. At present, therapeutics that regulate multiple targets and pathways are regarded as an alternative method in the management of cancers such as prostate cancer (83). GFW may exert therapeutic effects against uterine fibroids through multi-pathway and -target activity.

According to the current predictions based on network pharmacology, a number of novel signaling pathways and biological processes underlying the effects of GFW on uterine fibroids were identified. The results also provided a rationale for the combination of herbs within GFW. This network pharmacology method may aid the systematical study of herbal formulae and make TCM drug discovery more predictable. Evaluating the efficacy of TCM recipes and identifying the corresponding pharmacological mechanism on a systematic level may be a useful method for future studies.

\section{Acknowledgements}

The present study was supported by the National Natural Science Foundation of China (grant no. 81303123)

\section{References}

1. Townsend DE, Sparkes RS, Baluda MC and McClelland G: Unicellular histogenesis of uterine leiomyomas as determined by electrophoresis by glucose-6-phosphate dehydrogenase. Am J Obstet Gynecol 107: 1168-1173, 1970.

2. Pandis N, Heim S, Bardi G, Flodérus UM, Willén H, Mandahl N and Mitelman F: Chromosome analysis of 96 uterine leiomyomas. Cancer Genet Cytogenet 55: 11-18, 1991.

3. Rein MS: Advances in uterine leiomyoma research: The progesterone hypothesis. Environ Health Perspect 108 (Suppl 5): S791-S793, 2000.

4. Borahay MA, Al-Hendy A, Kilic GS and Boehning D: Signaling pathways in leiomyoma: Understanding pathobiology and implications for therapy. Mol Med 21: 242-256, 2015.

5. Levy BS: Modern management of uterine fibroids. Acta Obstet Gynecol Scand 87: 812-823, 2008.

6. Maruo T, Ohara N, Wang J and Matsuo H: Sex steroidal regulation of uterine leiomyoma growth and apoptosis. Hum Reprod Update 10: 207-220, 2004.

7. Grigorieva V, Chen-Mok M, Tarasova M and Mikhailov A: Use of a levonorgestrel-releasing intrauterine system to treat bleeding related to uterine leiomyomas. Fertil Steril 79: 1194-1198, 2003.

8. Falcone T, Bedaiwy MA: Minimally invasive management of uterine fibroids. Curr Opin Obstet Gynecol 14: 401-407, 2002.

9. Lethaby A, Vollenhoven B and Sowter M: Pre-operative GnRH analogue therapy before hysterectomy or myomectomy for uterine fibroids. Cochrane Database Syst Rev: CD000547, 2001.

10. Tristan M, Orozco LJ, Steed A, Ramírez-Morera A and Stone P: Mifepristone for uterine fibroids. Cochrane Database Syst Rev: doi: 10.1002/14651858.CD007687.pub2.

11. Lumsden MA: Modern management of fibroids. Obstet Gynaecol Reprod Med 20: 82-86, 2010.

12. Walker CL and Stewart EA: Uterine fibroids: The elephant in the room. Science 308: 1589-1592, 2005.

13. Lethaby A, Vollenhoven B and Sowter M: Efficacy of pre-operative gonadotrophin hormone releasing analogues for women with uterine fibroids undergoing hysterectomy or myomectomy: A systematic review. BJOG 109: 1097-1108, 2002.

14. Sankaran S and Manyonda IT: Medical management of fibroids. Best Pract Res Clin Obstet Gynaecol 22: 655-676, 2008.

15. Yan J, Li CP and Liu SS: Study of disease names treated by Guizhi Fuling pills based on data mining technology. Chin J Mod Drug Appl 6: 85-86, 2012 (In Chinese).

16. Fan YS: Jin Gui Yao Lue. China Press of Traditional Chinese Medicine, Beijing, 2007.

17. National Commission of Chinese Pharmacopoeia: Pharmacopoeia of the People's Republic of China. Beijing China Med Scie Technol Press 1: 984, 2010 (In Chinese).

18. Chen NN, Han M, Yang H, Yang GY, Wang YY, Wu XK and Liu JP: Chinese herbal medicine Guizhi Fuling Formula for treatment of uterine fibroids: A systematic review of randomised clinical trials. BMC Complement Altern Med 14: 2, 2014.

19. Liu AL and Du GH: Network pharmacology: New guidelines for drug discovery. Yao Xue Xue Bao 45: 1472-1477, 2010 (In Chinese).

20. Liang X, Li H and Li S: A novel network pharmacology approach to analyse traditional herbal formulae: The Liu-Wei-Di-Huang pill as a case study. Mol Biosyst 10: 1014-1022, 2014. 
21. Li S, Zhang B, Jiang D, Wei Y and Zhang N: Herb network construction and co-module analysis for uncovering the combination rule of traditional Chinese herbal formulae. BMC Bioinformatics 11 (Suppl 11): S6, 2010.

22. Zheng CS, Xu XJ, Ye HZ, Wu GW, Li XH, Xu HF and Liu XX: Network pharmacology-based prediction of the multi-target capabilities of the compounds in Taohong Siwu decoction, and their application in osteoarthritis. Exp Ther Med 6: 125-132, 2013.

23. Chen FP, Chang CM, Hwang SJ, Chen YC and Chen FJ: Chinese herbal prescriptions for osteoarthritis in Taiwan: Analysis of National Health Insurance dataset. BMC Complement Altern Med 14: 91, 2014.

24. Ru J, Li P, Wang J, Zhou W, Li B, Huang C, Li P, Guo Z, Tao W, Yang Y, et al: TCMSP: A database of systems pharmacology for drug discovery from herbal medicines. J Cheminform 6: 13 , 2014.

25. Chen L, Wang D, Wu J, Yu B and Zhu D: Identification of multiple constituents in the traditional Chinese medicine formula GuiZhiFuLing-Wan by HPLC-DAD-MS/MS. J Pharm Biomed Anal 49: 267-275, 2009

26. Liu X, Ouyang S, Yu B, Liu Y, Huang K, Gong J, Zheng S, Li Z, Li H and Jiang H: PharmMapper server: A web server for potential drug target identification using pharmacophore mapping approach. Nucleic Acids Res 38 (Web Server Issue): W609-W614, 2010.

27. Hamosh A, Scott AF, Amberger JS, Bocchini CA and McKusick VA: Online Mendelian Inheritance in Man (OMIM), a knowledgebase of human genes and genetic disorders. Nucleic Acids Res 33 (Database Issue): D514-D517, 2005.

28. Szklarczyk D, Franceschini A, Wyder S, Forslund K, Heller D, Huerta-Cepas J, Simonovic M, Roth A, Santos A, Tsafou KP, et al: STRING v10: Protein-protein interaction networks, integrated over the tree of life. Nucleic Acids Res 43 (Database Issue) D447-D452, 2015

29. Orchard S, Ammari M, Aranda B, Breuza L, Briganti L, Broackes-Carter F, Campbell NH, Chavali G, Chen C, del-Toro N, et al: The MIntAct project-IntAct as a common curation platform for 11 molecular interaction databases. Nucleic Acids Res 42 (Database Issue): D358-D363, 2014.

30. Franz M, Lopes CT, Huck G, Dong Y, Sumer O and Bader GD Cytoscape.js: A graph theory library for visualisation and analysis. Bioinformatics 32: 309-311, 2016

31. Missiuro PV, Liu K, Zou L, Ross BC, Zhao G, Liu JS and $\mathrm{Ge} \mathrm{H}$ : Information flow analysis of interactome networks. PLoS Comput Biol 5: e1000350, 2009.

32. Raman K, Damaraju N and Joshi GK: The organisational structure of protein networks: Revisiting the centrality-lethality hypothesis. Syst Synth Biol 8: 73-81, 2014.

33. Zhang Y, Bai M, Zhang B, Liu C, Guo Q, Sun Y, Wang D, Wang C, Jiang Y, Lin N and Li S: Uncovering pharmacological mechanisms of Wu-tou decoction acting on rheumatoid arthritis through systems approaches: Drug-target prediction, network analysis and experimental validation. Sci Rep 5: 9463 , 2015.

34. Huang da W, Sherman BT and Lempicki RA: Systematic and integrative analysis of large gene lists using DAVID bioinformatics resources. Nat Protoc 4: 44-57, 2009.

35. Farber M, Conrad S, Heinrichs WL and Herrmann WL: Estradiol binding by fibroid tumors and normal myometrium. Obste Gynecol 40: 479-486, 1972

36. Puukka MJ, Kontula KK, Kauppila AJ, Janne OA and Vihko RK: Estrogen receptor in human myoma tissue. Mol Cell Endocrinol 6: 35-44, 1976.

37. Kim JJ, Sefton EC and Bulun SE: Progesterone receptor action in leiomyoma and endometrial cancer. Prog Mol Biol Transl Sci 87 53-85, 2009.

38. Kim JJ, Kurita T and Bulun SE: Progesterone action in endometrial cancer, endometriosis, uterine fibroids, and breast cancer. Endocr Rev 34: 130-162, 2013

39. Islam MS, Protic O, Stortoni P, Grechi G, Lamanna P, Petraglia F, Castellucci M and Ciarmela P: Complex networks of multiple factors in the pathogenesis of uterine leiomyoma. Fertil Steril 100: 178-193, 2013

40. Ciarmela P, Islam MS, Reis FM, Gray PC, Bloise E, Petraglia F, Vale $\mathrm{W}$ and Castellucci M: Growth factors and myometrium: Biological effects in uterine fibroid and possible clinical implications. Hum Reprod Update 17: 772-790, 2011.

41. Marsh EE and Bulun SE: Steroid hormones and leiomyomas. Obstet Gynecol Clin North Am 33: 59-67, 2006.
42. Sozen I and Arici A: Interactions of cytokines, growth factors, and the extracellular matrix in the cellular biology of uterine leiomyomata. Fertil Steril 78: 1-12, 2002.

43. Nierth-Simpson EN, Martin MM, Chiang TC, Melnik LI, Rhodes LV, Muir SE, Burow ME and McLachlan JA: Human uterine smooth muscle and leiomyoma cells differ in their rapid 17beta-estradiol signaling: Implications for proliferation. Endocrinology 150: 2436-2445, 2009.

44. Benassayag C, Leroy MJ, Rigourd V, Robert B, Honoré JC, Mignot TM, Vacher-Lavenu MC, Chapron $\mathrm{C}$ and Ferré F: Estrogen receptors (ERalpha/ERbeta) in normal and pathological growth of the human myometrium: Pregnancy and leiomyoma. Am J Physiol 276: E1112-E1118, 1999.

45. Kovács KA, Oszter A, Göcze PM, Környei JL and Szabó I: Comparative analysis of cyclin D1 and oestrogen receptor (alpha and beta) levels in human leiomyoma and adjacent myometrium. Mol Hum Reprod 7: 1085-1091, 2001.

46. Maekawa R, Sato S, Yamagata Y, Asada H, Tamura I, Lee L, Okada M, Tamura H, Takaki E, Nakai A and Sugino N: Genome-wide DNA methylation analysis reveals a potential mechanism for the pathogenesis and development of uterine leiomyomas. PLoS One 8: e66632, 2013.

47. Ishikawa H, Ishi K, Serna VA, Kakazu R, Bulun SE and Kurita T: Progesterone is essential for maintenance and growth of uterine leiomyoma. Endocrinology 151: 2433-2442, 2010.

48. Lange CA: Integration of progesterone receptor action with rapid signaling events in breast cancer models. J Steroid Biochem Mol Biol 108: 203-212, 2008

49. Boonyaratanakornkit V, Scott MP, Ribon V, Sherman L, Anderson SM, Maller JL, Miller WT and Edwards DP Progesterone receptor contains a proline-rich motif that directly interacts with $\mathrm{SH} 3$ domains and activates c-Src family tyrosine kinases. Mol Cell 8: 269-280, 2001.

50. Maruo T, Matsuo H, Samoto T, Shimomura Y, Kurachi O, Gao Z, Wang Y, Spitz IM and Johansson E: Effects of progesterone on uterine leiomyoma growth and apoptosis. Steroids 65: 585-592, 2000.

51. Shimomura Y, Matsuo H, Samoto T and Maruo T: Up-regulation by progesterone of proliferating cell nuclear antigen and epidermal growth factor expression in human uterine leiomyoma. J Clin Endocrinol Metab 83: 2192-2198, 1998.

52. Burroughs KD, Howe SR, Okubo Y, Fuchs-Young R, LeRoith D and Walker CL: Dysregulation of IGF-I signaling in uterine leiomyoma. J Endocrinol 172: 83-93, 2002.

53. Peng L, Wen Y, Han Y, Wei A, Shi G, Mizuguchi M, Lee P, Hernando E, Mittal K and Wei JJ: Expression of insulin-like growth factors (IGFs) and IGF signaling: Molecular complexity in uterine leiomyomas. Fertil Steril 91: 2664-2675, 2009.

54. Chang CC, Hsieh YY, Lin WH and Lin CS: Leiomyoma and vascular endothelial growth factor gene polymorphisms: A systematic review. Taiwan J Obstet Gynecol 49: 247-253, 2010.

55. Rossi MJ, Chegini N and Masterson BJ: Presence of epidermal growth factor, platelet-derived growth factor, and their receptors in human myometrial tissue and smooth muscle cells: Their action in smooth muscle cells in vitro. Endocrinology 130: 1716-1727, 1992.

56. Helmke BM, Markowski DN, Müller MH, Sommer A, Müller J, Möller C and Bullerdiek J: HMGA proteins regulate the expression of FGF2 in uterine fibroids. Mol Hum Reprod 17: 135-142, 2011.

57. Kolch W: Meaningful relationships: The regulation of the Ras/Raf/MEK/ERK pathway by protein interactions. Biochem J 351: 289-305, 2000.

58. Crabtree JS, Jelinsky SA, Harris HA, Choe SE, Cotreau MM, Kimberland ML, Wilson E, Saraf KA, Liu W, McCampbell AS, et al: Comparison of human and rat uterine leiomyomata: Identification of a dysregulated mammalian target of rapamycin pathway. Cancer Res 69: 6171-6178, 2009.

59. Swartz CD, Afshari CA, Yu L, Hall KE and Dixon D: Estrogen-induced changes in IGF-I, Myb family and MAP kinase pathway genes in human uterine leiomyoma and normal uterine smooth muscle cell lines. Mol Hum Reprod 11: 441-450, 2005.

60. Yu L, Saile K, Swartz CD, He H, Zheng X, Kissling GE, Di X, Lucas S, Robboy SJ and Dixon D: Differential expression of receptor tyrosine kinases (RTKs) and IGF-I pathway activation in human uterine leiomyomas. Mol Med 14: 264-275, 2008.

61. Karra L, Shushan A, Ben-Meir A, Rojansky N, Klein BY, Shveiky D, Levitzki R and Ben-Bassat H: Changes related to phosphatidylinositol 3-kinase/Akt signaling in leiomyomas: Possible involvement of glycogen synthase kinase 3alpha and cyclin D2 in the pathophysiology. Fertil Steril 93: 2646-2651, 2010. 
62. Jeong YJ, Noh EM, Lee YR, Yu HN, Jang KY, Lee SJ, Kim J and Kim JS: $17 \beta$-estradiol induces up-regulation of PTEN and PPAR $\gamma$ in leiomyoma cells, but not in normal cells. Int $J$ Oncol 36: 921-927, 2010

63. Chegini N, Luo X, Ding L and Ripley D: The expression of Smads and transforming growth factor beta receptors in leiomyoma and myometrium and the effect of gonadotropin releasing hormone analogue therapy. Mol Cell Endocrinol 209: 9-16, 2003.

64. Fayed YM, Tsibris JC, Langenberg PW and Robertson AL Jr: Human uterine leiomyoma cells: Binding and growth responses to epidermal growth factor, platelet-derived growth factor, and insulin. Lab Invest 60: 30-37, 1989.

65. Ren Y, Yin H, Tian R, Cui L, Zhu Y, Lin W, Tang XD, Gui Y and Zheng XL: Different effects of epidermal growth factor on smooth muscle cells derived from human myometrium and from leiomyoma. Fertil Steril 96: 1015-1020, 2011.

66. Brown LF, Detmar M, Tognazzi K, Abu-Jawdeh G and Iruela-Arispe ML: Uterine smooth muscle cells express functional receptors (flt-1 and KDR) for vascular permeability factor/vascular endothelial growth factor. Lab Invest 76: 245-255, 1997.

67. Sanci M, Dikis C, Inan S, Turkoz E, Dicle N and Ispahi C: Immunolocalization of VEGF, VEGF receptors, EGF-R and $\mathrm{Ki}-67$ in leiomyoma, cellular leiomyoma and leiomyosarcoma. Acta Histochem 113: 317-325, 2011

68. Gentry CC, Okolo SO, Fong LF, Crow JC, Maclean AB and Perrett CW: Quantification of vascular endothelial growth factor-A in leiomyomas and adjacent myometrium. Clin Sci (Lond) 101: 691-695, 2001.

69. Ono M, Yin P, Navarro A, Moravek MB, Coon JS V, Druschitz SA, Serna VA, Qiang W, Brooks DC, Malpani SS, et al: Paracrine activation of $\mathrm{WNT} / \beta$-catenin pathway in uterine leiomyoma stem cells promotes tumor growth. Proc Natl Acad Sci USA 110: 17053-17058, 2013.

70. Catherino WH and Malik M: Uterine leiomyomas express a molecular pattern that lowers retinoic acid exposure. Fertil Steril 87: 1388-1398, 2007

71. Olive DL, Lindheim SR and Pritts EA: Non-surgical management of leiomyoma: Impact on fertility. Curr Opin Obstet Gynecol 16 239-243, 2004

72. Fiscella K, Eisinger SH, Meldrum S, Feng C, Fisher SG and Guzick DS: Effect of mifepristone for symptomatic leiomyomata on quality of life and uterine size: A randomized controlled trial. Obstet Gynecol 108: 1381-1387, 2006.

73. Donnez J, Tatarchuk TF, Bouchard P,Puscasiu L, Zakharenko NF, Ivanova T, Ugocsai G, Mara M, Jilla MP, Bestel E, et al: Ulipristal acetate versus placebo for fibroid treatment before surgery. N Engl J Med 366: 409-420, 2012.
74. Xu Q, Ohara N, Chen W, Liu J, Sasaki H, Morikawa A, Sitruk-Ware R, Johansson ED and Maruo T: Progesterone receptor modulator CDB-2914 down-regulates vascular endothelial growth factor, adrenomedullin and their receptors and modulates progesterone receptor content in cultured human uterine leiomyoma cells. Hum Reprod 21: 2408-2416, 2006.

75. Ohara N, Morikawa A, Chen W, Wang J, DeManno DA, Chwalisz $\mathrm{K}$ and Maruo T: Comparative effects of SPRM asoprisnil (J867) on proliferation, apoptosis, and the expression of growth factors in cultured uterine leiomyoma cells and normal myometrial cells. Reprod Sci 14 (8 Suppl): S20-S27, 2007.

76. Eisinger SH, Bonfiglio T, Fiscella K, Meldrum S and Guzick DS: Twelve-month safety and efficacy of low-dose mifepristone for uterine myomas. J Minim Invasive Gynecol 12: 227-233, 2005.

77. Boettger-Tong H, Shipley G, Hsu CJ and Stancel GM: Cultured human uterine smooth muscle cells are retinoid responsive. Proc Soc Exp Biol Med 215: 59-65, 1997.

78. Norian JM, Owen CM, Taboas J, Korecki C, Tuan R, Malik M, Catherino WH and Segars JH: Characterization of tissue biomechanics and mechanical signaling in uterine leiomyoma. Matrix Biol 31: 57-65, 2012

79. Rogers R, Norian J, Malik M, Christman G, Abu-Asab M, Chen F, Korecki C, Iatridis J, Catherino WH, Tuan RS, et al: Mechanical homeostasis is altered in uterine leiomyoma. Am J Obstet Gynecol 198: 474.e1-e11, 2008.

80. Xu HY, Chen ZW and Wu YM: Antitumor activity of total paeony glycoside against human chronic myelocytic leukemia K562 cell lines in vitro and in vivo. Med Oncol 29: 1137-1147, 2012.

81. Tao XQ, Li N, Cao L, Zhang CF, Wang TJ, Ding G, Wang ZZ and Xiao W: Effect of main components from Guizhi Fuling capsule on human leiomyoma cell proliferation and contraction of isolated mouse uterine. Chin J Exp Tradit Med Form 2: 91-96, 2016.

82. Lu CC, Shen $\mathrm{CH}$, Chang CB, Hsieh HY, Wu JD, Tseng LH, Hwang DW, Chen SY, Wu SF, Chan MW and Hsu CD: Guizhi Fuling Wan as a novel agent for intravesical treatment for bladder cancer in mouse model. Mol Med: Jan 13, 2016 (Epub ahead of print).

83. McCarty MF: Targeting multiple signaling pathways as a strategy for managing prostate cancer: Multifocal signal modulation therapy. Integr Cancer Ther 3: 349-380, 2004. 